\title{
KARAKTERISTIK IBU DAN POST NATAL TREATMENT (PNT) BERHUBUNGAN DENGAN TERJADINYA POSTPARTUM BLUES IBU NIFAS
}

\author{
Yuliyanik \\ Sekolah Tinggi Ilmu Kesehatan Widyagma Husada \\ Program Studi DIII Kebidanan \\ E-mail :yulijuju67@yahoo.com
}

\begin{abstract}
This study aimed at examining the occurrence of postpartum blues in postpartum mothers. Post partum blues is categorized as a mild mental disorder syndrome for it is often ignored so that it is undiagnosed and not treated as it should, which finally leads to a difficult and unpleasant problem that may create feelings of discomfort for women who experience it. The study is intended to prevent the occurrence of Post partum blues in postpartum mothers. Post Partum Blues can be prevented by doing ANC and Post Natal Treatment routinely. Post Natal Treatment is a series of treatments performed specifically for postpartum mothers, which include massage, breast care, oxytocin massage, postpartum spa and full-blooded face. The research employed observational methods. The population of all puerperal mothers was 20 people, using total sampling. Data is obtained from primary data and secondary data, then the data is processed using SPSS 16 with chi square test. The conclusion of the value of $p=0.01$ is that there is a relationship between the characteristics of postpartum mothers and PNT with the occurrence of postpartum blues. Age, education and occupation of postpartum mothers are associated with the insidence of postpartum blues. PNT that had been received by postpartum mothers was also related to the insidence of postpartum blues. Researcher's suggestion is for postpartum mothers to carry out ANC and PNT routinely to prevent the occurrence of post partum blues.
\end{abstract}

Keyword: Breast milk; massage; oxytocin massage; postpartum mother.

\begin{abstract}
ABSTRAK
Penelitian ini dilakukan untuk mengetahui terjadinyapostpartum blues ibu nifas. Post partum blues ini dianggap sebagai gejala gangguan mental yang cukup ringan karena itu seringkali tidak dipedulikan sehingga tidak mudah terdeteksi dan tidak ditangani sebagaimana seharusnya, dan dapat menjadi masalah bagi ibu nifas, tidak menyenangkan dan dapat membuat perasaan perasaan tidak nyaman bagi wanita yang mengalaminya. Tujuan penelitian ini untuk mencegah terjadinya Postpartum blues pada ibu nifas. Postpartum Blues dapat dicegah dengan melakukan ANC dan Post Natal Treatment secara rutin. Post Natal Treatment adalah serangkaian perawatan yang dilakukan khusus pada ibu nifas, yaitu meliputi massage, perawatan payudara, pijat oksitosin, spa masa nifas dan totok wajah. Desain penelitian ini menggunakan metode observasional. Populasinya seluruh ibu masa nifas sebanyak 20 orang, menggunakan total

Cara mengutip: Yuliyanik. (2019).Karakteristik Ibu dan Post Natal treatment (PNT) Berhubungan dengan Terjadinya Post Partum Blues pada Ibu Nifas.Care:Jurnal Ilmiah Ilmu Kesehatan, 7(2), 69-75.


sampling. Data didapat dari dengan mengambil data primer dan sekunder, kemudian data diolah dengan menggunakan SPSS 16 dengan uji chi square. Kesimpulan dari nilai $\mathrm{p}=0,01$ adalah terdapat hubungan antara karakteristik ibu nifas dan PNT dengan kejadian postpartum blues. Usia, pendidikan dan pekerjaan ibu nifas berhubungan dengan kejadian postpartum blues. PNT yang pernah didapatkan ibu nifas juga berhubungan dengan kejadian postpartum blues. Saran peneliti adalah agar ibu nifas melakukan ANC dan PNT secara rutin untuk mencegah terjadinya postpartum blues.

Kata Kunci : ASI; ibu nifas; massage; pijat oksitosin.

\section{PENDAHULUAN}

Masa nifas adalah masa postpartum atau puerperium disebut juga masa sesudah persalinan, masa perubahan, pemulihan, penyembuhan, dan pengembalian alat-alat kandungan/reproduksi, seperti sebelum hamil yang lamanya 6 minggu atau 42 hari pasca persalinan (Bahiyatun, 2009). Saat melalui masa ini, tubuh mulai menyesuaikan diri baik secara fisik maupun psikososial sejak proses melahirkan yang dimulai segera setelah plasenta lahir sampai tubuh menyesuaikan diri pulih secara sempurna dan/atau berakhir ketika organ-organ kandungan kembali pada keadaan seperti sebelum hamil yang berlangsung selama 6 minggu atau 42 hari. Pada masa nifas ini terjadi perubahan-perubahan, yaitu perubahan fisiologi dan perubahan psikologi.

Jika reaksi fisiologi dan reaksi psikologi selama nifas ini tidak ditangani dengan baik, maka dapat terjadi postpartum blues yaitu kecemasan yang terjadi setelah persalinan. Postpartum blues ini dianggap sebagai sindroma gangguan mental yang ringan karena itu sering tidak ditangani dengan cepat karena tidak terdiagnosis sehingga tata laksananya tidak sebagaimana seharusnya, pada akhirnya dapat menjadi masalah yang sulit, tidak menyenangkan dan dapat menjadikan rasa tidak nyaman bagi wanita yang mengalaminya, dan bahkan terkadang gangguan ini berkembang menjadi lebih berat yaitu depresi dan psikosis pasca-salin, berakibat lebih buruk, terutama dalam masalah hubungan rumah tangga, serta pertumbuhan dan perkembangan anaknya (Zubaran et al., 2010).Penelitian ini penting dilakukan, karena masih adanya ibu nifas yang tidak melakukan PNT untuk mencegah terjadinya postpartum blues. postpartum blues dapat dicegah jika selama masa kehamilan/Ante Natal Care (ANC), ibu melakukan pemeriksaan secara rutin dan melaksanakan saran dari tenaga kesehatan. Melakukan ANC secara rutin membuat ibu memahami hal-hal atau 
perubahan yang terjadi selama kehamilan, persalinan dan nifas.

Ibu juga memahami perubahan yang terjadi selama proses masa nifasnya, yang jika tidak ditangani dengan baik dapat menyebabkan terjadinyap Postpartum blues. Postpartum blues dapat dicegah dengan dilakukannya Post Natal Treatment. Post Natal Treatment adalah serangkaian perawatan yang dilakukan khusus pada ibu nifas, yaitu meliputi massage, perawatan payudara, pijat oksitosin, spa masa nifas dan totok wajah. Post Natal Treatment dilakukan agar ibu nifas dapat melalui masa nifas dengan baik tanpa komplikasi.

Perawatan yang dilakukan dapat membuat ibu nifas lebih segar sehingga proses involusi dapat berjalan dengan lancar tanpa masalah/komplikasi (Mirzaei et al., 2016). Latarbelakang dari permasalahan ini, antara lain kurangnya pengetahuan ibu masa nifas tentang terjadinya postpartum blues, kurangnya pengetahuan dan keterampilan ibu nifas tentang pijat oksitosin, banyaknya ibu nifas yang ASI nya tidak lancar, kurangnya pengetahuan ibu tentang post natal treatment. Tujuan dilakukan penelitian ini untuk mencegah terjadinya post partum blues dan meningkatkan pengetahuan serta ketrampilan ibu nifas tentang post natal treatment.

\section{METODE PENELITIAN}

Desain dalam penelitian ini menggunakan metode observasional. Jumlah populasi dalam penelitian ini adalah seluruh ibu nifas yang ada di Posyandu, jumlah sampel sebanyak 20 responden dengan mengguakan total sampling. Instrumen yang digunakan adalah kuesioner. Kriteria inklusi meliputi ibu nifas yang datang periksa ke posyandu pada saat penelitian. Metode pengumpulan data di peroleh dari data primer dengan wawancara langsung kepada responden dan memberikan kuesioner serta data sekunder. Analisa data diolah dengan menggunakan SPSS 16 dengan uji chi square.

\section{HASIL}

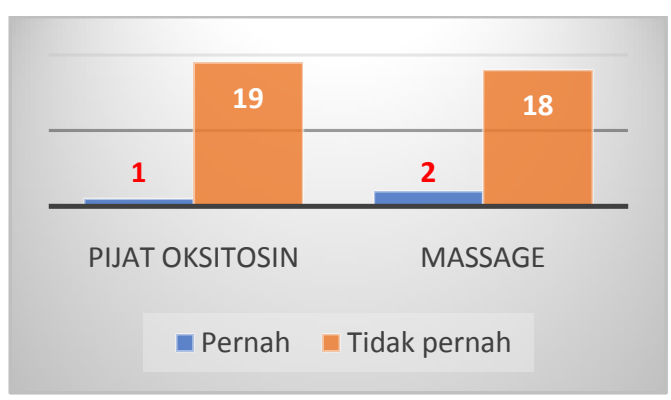

Gambar 1. Distribusi frekuensi tentang Post Natal Treatment Ibu Nifas di Posyandu Melati RT 04 RW 6 Kel. Tasikmadu Kec. Lowokwaru Kota Malang Tahun 2018

Berdasarkan Gambar 1 dapat dilihat bahwa ibu nifas terbanyak tidak pernah melakukan pijat oksitosin yaitu sebanyak 19 orang dan yang tidak pernah melakukan massage sebanyak 18 orang. 
Gambar 2 dapat dilihat bahwa ibu nifas terbanyak mengalami Post Partum Blues yaitu sebanyak 16 orang.

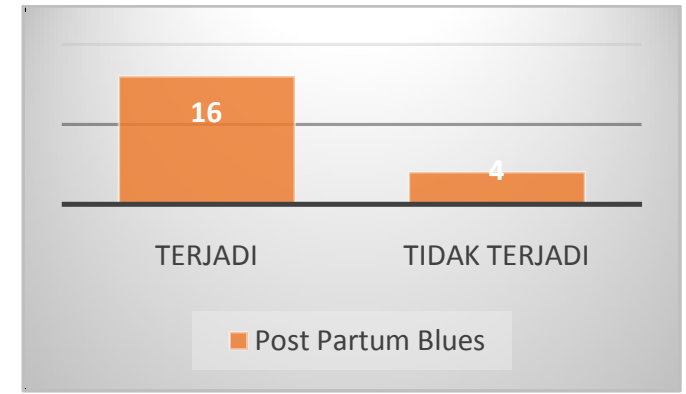

Gambar 2. Distribusi frekuensi tentang Postpartum Blues Ibu Nifas di Posyandu Melati RT 04 RW 6 Kel.T asikmadu Kec. Lowokwaru Kota Malang tahun 2018

Tabel1. Hasil uji statistic hubungan post natal treatment (pijatoksitosin) dengan kejadian postpartum blues

\begin{tabular}{|c|c|c|c|c|c|}
\hline & Value & df & $\begin{array}{l}\text { Asymp. Sig. } \\
\text { (2-sided) }\end{array}$ & $\begin{array}{l}\text { Exact Sig. } \\
\text { (2-sided) }\end{array}$ & $\begin{array}{l}\text { Exact Sig. } \\
\text { (1-sided) }\end{array}$ \\
\hline $\begin{array}{l}\text { Pearson Chi-Square } \\
\text { Continuity Correction }{ }^{2}\end{array}$ & $\begin{array}{l}4.211^{\mathrm{a}} \\
.592\end{array}$ & $\begin{array}{l}1 \\
1\end{array}$ & $\begin{array}{l}.040 \\
.442\end{array}$ & & \\
\hline $\begin{array}{l}\text { Likelihood Ratio } \\
\text { Fisher's Exact Test } \\
\text { Linear-by-Linear } \\
\text { Association } \\
\mathrm{N} \text { or Valid Cases }\end{array}$ & $\begin{array}{c}3.442 \\
4.000 \\
20\end{array}$ & 1 & $\begin{array}{l}.064 \\
.046\end{array}$ & .200 & .200 \\
\hline
\end{tabular}

Tabel 1 didapatkan nilai $\mathrm{p}=0,04$, dimana $\mathrm{p}<0,05$ artinya bahwa terdapat hubungan antara pijat oksitosin dengan kejadian post partum blues, sedangkan Tabel 2 didapatkan nilai $\mathrm{p}=0,03$, dimana $\mathrm{p}<0,05$ artinya bahwa terdapat hubungan antara massage dengan kejadian post partum blues.

Tabel 2. Hasil uji statistic hubunganpost natal treatment (massage) dengankejadianpost partum blues

\begin{tabular}{lccccc}
\hline & Value & $\mathrm{df}$ & $\begin{array}{c}\text { Asymp. Sig. } \\
\text { (2-sided) }\end{array}$ & $\begin{array}{c}\text { Exact Sig. } \\
(2 \text {-sided })\end{array}$ & $\begin{array}{c}\text { Exact Sig. } \\
\text { (1-sided) }\end{array}$ \\
\hline Pearson Chi-Square & $8.889^{\mathrm{a}}$ & 1 & .003 & & \\
$\begin{array}{l}\text { Continuity Correction } \\
{ }^{2}\end{array}$ & 4.201 & 1 & .040 & & \\
$\begin{array}{l}\text { Likelihood Ratio } \\
\begin{array}{l}\text { Fisher's Exact Test } \\
\text { Linear-by-Linear }\end{array}\end{array}$ & 7.458 & 1 & .006 & & .032 \\
$\begin{array}{l}\text { Association } \\
\text { N or Valid Cases }\end{array}$ & 8.444 & 1 & .004 & & \\
\hline
\end{tabular}

\section{PEMBAHASAN}

Pada hasil penelitian tentang usia ibu nifas, sebagian besar ibu nifas usianya 26-30 tahun sebanyak 11 orang (55\%), dan 
didapatkan hasil output menunjukkan nilai signifikansi korelasi sebesar 0,001, dimana nilai tersebut lebih kecil dari nilai taraf signifikansi yang digunakan yaitu $5 \%$ atau 0.05, maka dapat disimpulkan bahwa ada hubungan antara usia dengan kejadian Post Partum Blues pada ibu nifas.

Responden dengan usia tersebut paling banyak yang menganggap bahwa dengan usia yang sudah matang dianggap sudah dapat menyelesaikan sendiri keluhan atau masalah yang dihadapi selama masa nifasnya. Pada data tentang Pendidikan ibunifas, sebagian besar ibu nifas berpendidikan SMA sebanyak 12 orang (60\%), dimana seseorang dengan latarbelakang Pendidikan SMA termasuk dalam Pendidikan tinggi.

Hasil uji analisis bivariat menggunakan uji chi square dengan software SPSS 16 didapatkan hasil output menunjukkan nilai signifikansi korelasi sebesar 0,001, dimana nilai tersebut lebih kecil dari nilai taraf signifikansi yang digunakan yaitu $5 \%$ atau 0.05, maka dapat disimpulkan bahwa ada hubungan antara pendidikan dengan kejadian postpartum blues pada ibu nifas.

Seseorang dengan pendidikan SMA diharapkan dapat memahami informasi yang mereka dapatkan baik dari media massa maupun dari orang lain tentang masalah kesehatan terutama tentang hal-hal yang terkait dengan ibu nifas. Pada data tentang pekerjaan, sebagian besar pekerjaan ibu nifas sebagai ibu rumah tangga sebanyak 13 orang (65\%). Hasil uji analisis bivariat menggunakan uji chi square dengan software SPSS 16 didapatkan hasil output menunjukkan nilai signifikansi korelasi sebesar 0,002, dimana nilai tersebut lebih kecil dari nilai taraf signifikansi yang digunakan yaitu $5 \%$ atau 0,05, maka dapat disimpulkan adanya hubungan antara pekerjaan dengan kejadian postpartum blues pada ibu nifas.

Sebagai ibu rumah tangga dapat menjadi pengaruh untuk mendapatkan informasi yang kurang tentang kesehatan yang terkait dengan permasalahan yang seringkali dialami oleh ibu tersebut. Ibu nifas sebagai ibu rumah tangga terkadang ada yang kurang mendapatkan info tentang kesehatan karena jarang membaca, melihat atau mendengar tentang masalah kesehatan seputar ibu nifas.

Pada Gambar 1, distribusi frekuensi tentang post natal treatment, dapat dilihat bahwa sebagian besar ibu nifas belum pernah mendapatkan post natal treatment, yaitu pijat oksitosin sebanyak 19 orang (95\%), sedangkan massage sebanyak 18 orang $(90 \%)$. Hasil uji analisis bivariat menggunakan uji chi square dengan software 
SPSS 16 menunjukkan hasil nilai signifikansi korelasi sebesar 0,040 untuk pijat oksitosin dan 0,003 untuk massage, dimana nilai tersebut lebih kecil dari taraf signifikansi yang digunakan yaitu 5\% atau 0.05, maka dapat disimpulkan bahwaada hubungan antara Post Natal Treatment(pijat oksitosin dan massage) dengan kejadian postpartum blues pada ibu nifas.

Dari hasil tersebut dapat dilihat bahwa masih banyak ibu nifas yang belum pernah mendapatkan post natal treatment yaitu pijat oksitosin dan massage, dimana hal tersebut merupakan tindakan yang dapat membantu agar ASI ibu dapat keluar dengan lancar dan ibu nifas juga merasa segar dan nyaman selama menghadapi masa nifasnya. Masa nifas yang dapat dilalui ibu dengan nyaman, sangat membantu dalam involusi uterus, membantu ASI keluar dengan lancar, sehingga ibu dapat melalui masa nifasnya dengan tenang.

Jika ibu tenang, maka bayi juga akan tenang karena ASI keluar dengan lancar yang dapat menyebabkan bayi tidur nyenyak, BB bayi juga bertambah sehingga bayi dapat tumbuh dengan sehat. Pada Gambar 2, dapat dilihat bahwa sebagian besar ibu nifas terjadi postpartum blues sebanyak 16 orang $(80 \%)$. Ibu nifas tidak menyadari bahwa ibu mengalami postpartum blues, hal ini terjadi karena masalah atau keluhan yang dialami ibu nifas dianggap suatu hal yang biasa dialami oleh ibu-ibu setelah melahirkan bayinya.

Ibu merasa kelelahan, ibu harus merawat bayinya sendiri tanpa bantuan dari suami, ibu yang harus meneteki bayinya, semua hal itu oleh ibu dianggap sesuatu hal yang memang harus dilakukan oleh seorang ibu setelah melahirkan. Sehingga tanpa sadar, kelelahan yang berkepanjangan dapat mempengaruhi ibu dalam proses masa nifasnya. Hal-hal yang seharusnya bisa dikerjakan Bersama suami atau perlu dukungan suami, tidak didapatkan oleh ibu, sehingga ibu melakukan semuanya sendiri.

\section{KESIMPULAN}

Kesimpulan hasil penelitian ini adalah, adanya hubungan antara usia, pendidikan, pekerjaan dan post natal treatmen (pijat oksitosin dan massage) dengan terjadinya postpartum blues.

\section{SARAN}

Bagi peneliti selanjutnya adalah dapat mengkaji lebih mendalam sampai seberapa jauh ibu mengalami kejadian post partum blues terkait hubungannya dengan post natal treatment. 


\section{UCAPAN TERIMAKASIH}

Terselesaikannya penelitian ini, tidak lupa penulis mengucapkan terima kasih kepada Dr. Rudy Joegijantoro, MMRS selaku Ketua STIKES Widyagama Husada Malang, Ketua Lembaga Penelitian Pengabdian Masyarakat dan Kewirausahaan, Ketua PosyanduMelati RT 04 RW 06 Kel. Tasikmadu Kec. Lowokwaru Kota Malang, seluruh kader dan seluruh responden ibu nifas di Posyandu Melati RT 04 RW 06 Kel. Tasikmadu Kec. Lowokwaru Kota Malang, mahasiswa Prodi DIII Kebidanan STIKES Widyagama Husada, dan seluruh pihak yang telah mendukung penelitian ini, yang tidak bisa kami sebutkan satu persatu.

\section{REFERENSI}

Bahiyatun. (2009). Buku Ajar Asuban Kebidanan Nifas Normal. Jakarta: Penerbit Buku Kedokteran EGC.

Mirzaei Kh, Oladi Ghadikolaee S, Mousavi Bazzaz M, Z. M. (2016). Mother's satisfaction of postpartum care and its relationship with midwifery care at Urban Health Centers, Mashhad, Iran. Journal of Midwifery and Reproductive Health, 4(3), 679-688.

Zubaran, C, Schumacher, M., Roxo, M. R. \& Foresti, K. (2010). Screening tools for postpartum depression : validity and cultural dimension. Afr J Psychiatry (Johannesbg), 13(5), 357-65. 